\title{
ACIONAMENTO DE CARGA CA ATRAVÉS DE ONDAS SONORAS
}

\author{
LuCAS S. DE SOUSA, MARIA S. G. DE MACEDO, SANDRo C. S. JuCÁ
}

Laboratório de Sistemas Embarcados (LAESE), Depto. de Telemática. IFCE-Campus Maracanaú. Av. do Contorno Norte $n^{o} 10$ - Parque Central, Distrito Industrial - Maracanaú - CE

E-mails: Iucasssousalo@gmail.com, shirleymacedo89egmail.com, sandrojucalifce.edu.br

\begin{abstract}
This article consists in the design and implementation of a load control system through sound waves, captured by an electret microphone, which has its amplitude increased with the application of a pre-amplification circuit, which is powered by a symmetrical voltage adjustable source also designed with operational amplifiers. The analog sound wave is converted into a digital signal through the developed embedded system. This digital signal is also analyzed by the embedded system to control AC loads.
\end{abstract}

Keywords_ Amplifier, Electronics, Computation.

Resumo- O presente trabalho consiste no projeto e implementação de um sistema de controle de cargas através de ondas sonoras, captadas através de um microfone de eletreto, que tem amplitude aumentada através de um circuito de pré-amplificação, o qual é alimentado por uma fonte simétrica de tensão regulável projetada também com o uso de amplificador operacional. A onda sonora analógica é convertida em um sinal digital através do sistema embarcado desenvolvido. O sinal digital é analisado também pelo sistema embarcado para controlar cargas CA.

Palavras-chave— Amplificador, Eletrônica, Computação.

\section{Introdução}

Na natureza existem diversos tipos de sinais analógicos que podem ser aplicados em sistemas eletrônicos. Desde a radiação solar que é uma onda eletromagnética até uma onda sonora que é uma onda mecânica, os sinais podem ser lidos, digitalizados e processados por sistemas computacionais para controlar dispositivos e cargas eletro-eletrônicas.

Os sinais são lidos com o uso de sensores e transdutores que detectam as alterações causadas, gerando ondas equivalentes às emitidas pelas fontes, mas na forma de tensão. A partir daí, os sinais podem ser condicionados de várias formas e digitalizados para se adequar às várias aplicações proporcionadas pelos sistemas computacionais, como na atuação de relés para controlar a ligação de equipamentos eletroeletrônicos ou até mesmo na reprodução amplificada que é o caso das ondas sonoras detectadas por microfones e emitidas por auto-falantes.

No caso das ondas sonoras, estas são detectadas neste projeto por um dispositivo chamado de microfone de eletreto, o qual possui uma película fina de mylar que é carregada permanentemente em relação à armadura fixa que envolve o microfone, gerando uma onda que é inserida em um circuito de préamplificação para que o sinal seja detectado por um conversor analógico-digital (AD) de um microcontrolador.

Para gravar o firmware de controle e filtro digital no microcontrolador via USB, a partir de um PC, foi utilizada a ferramenta SanUSB, como também um compilador livre implementado na IDE livre MPLABX multiplataforma, com uma estrutura de controle de fluxo infinita criada em linguagem C (Schildt, 1996) para conversão em código hexadecimal gravado no microcontrolador via USB. O código do firmware controla e filtra perturbações no sinal gerado pelo eletreto, na forma digital, para que o sistema que se deseja manipular seja atuado.

\section{Desenvolvimento do projeto}

Este tópico descreve os componentes e as ferramentas utilizadas neste projeto.

\subsection{Fonte Simétrica}

O amplificador operacional é um componente que possui inúmeras aplicações nas mais diversas áreas tecnológicas. De modo geral, esses dispositivos estão presentes nos sistemas eletrônicos de controle e instrumentação industrial, na medicina (eletromedicina ou bioeletrônica), nos equipamentos de telecomunicações, nos equipamentos de áudio e nos sistemas de aquisição de dados (Marcelo Wendling, 2010). A simbologia do amplificador operacional é mostrada na figura 1 .

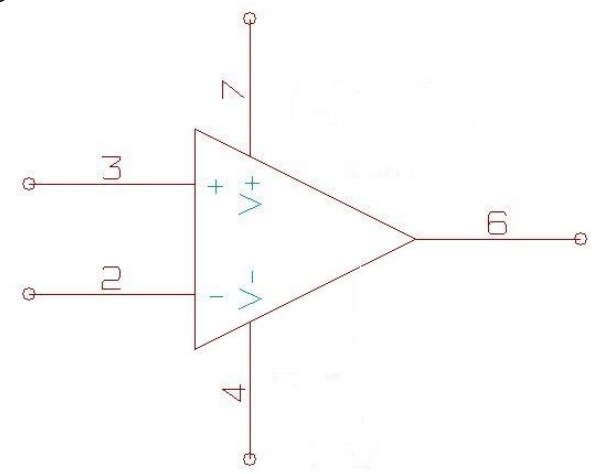

Figura 1. Simbologia do amplificador operacional 
As entradas 4 e 7, são utilizadas para alimentação Vcc(-) e Vcc(+), respectivamente. A entrada 3 é conhecida como não-inversora e a entrada 2 é conhecida como inversora. A saída 6 é baseada nas entradas 2, 3 e em um fator multiplicativo que é o ganho.

O amplificador utilizado possui basicamente dois tipos de operações. A primeira delas é em malha aberta, onde o ganho não é controlado e é utilizado, por exemplo, em comparadores tensão. A outra configuração é conhecida como malha fechada e classificadas de acordo com a forma da realimentação que pode ser negativa ou positiva. Circuitos com a realimentação positiva são estáveis, ou seja, o ganho é controlado e podem ser aplicados em osciladores. $\mathrm{O}$ amplificador operacional com realimentação negativa é a configuração mais utilizada. Pode ser aplicado em vários circuitos como amplificador não-inversor, somador, diferenciador, integrador, filtros ativos, etc.

A configuração do amplificador operacional na fonte simétrica atua como um isolador (buffer) de estágios, ilustrado na figura 2, que utiliza uma realimentação negativa e uma entrada na porta inversora. Fornece um ganho unitário sem a inversão da polaridade ou fase do sinal de entrada.

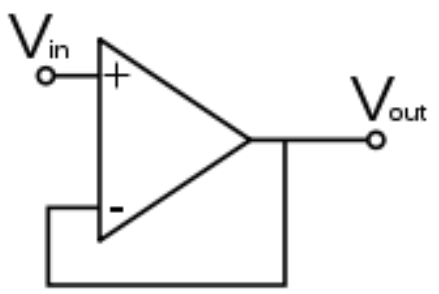

Figura 2. Buffer amplificador operacional

Na fonte simétrica, ilustrada na figura 3 , a tensão é dividida proporcionalmente à resistência de um potenciômetro de ajuste de forma que se estabeleça uma referência (ground) virtual localizada entre o GND e o Vcc da fonte utilizada para gerar a tensão. Assim, o valor da nova referência de tensão de saída ao +Vcc será uma tensão positiva e, consequentemente negativa em relação ao $-\mathrm{Vcc}$.

As tensões $+\mathrm{Vcc}$ e $-\mathrm{Vcc}$ são equilibradas com base no divisor de tensão utilizado no circuito de forma que quando as duas resistências são iguais, + Vcc e -Vcc são simétricos.

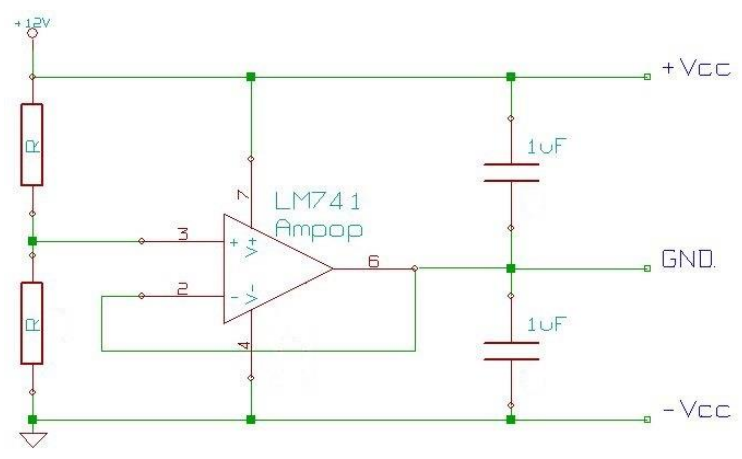

Figura 3. Circuito da fonte simétrica
Com o circuito da fonte simétrica, pode também ser extraída uma tensão assimétrica quando utilizamos apenas o GND e +Vcc, essa tensão pode ser regulada manualmente de $0 \mathrm{v}$ até a tensão da fonte que alimenta o circuito quando se utiliza um potenciômetro (Turner, 2004), ilustrado na figura 4, ao invés de resistores fixos.

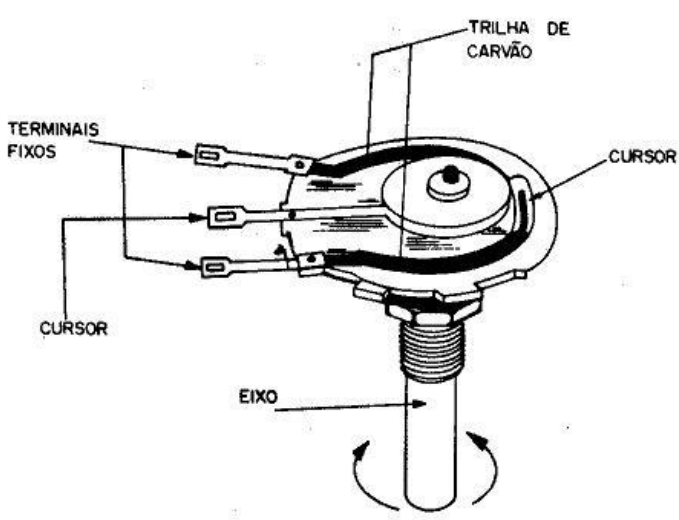

Figura 4. Potenciômetro

\subsection{Captação e amplificação de áudio}

Para realizar a captação do sinal de áudio, foi utilizado um sensor chamado de microfone de eletreto, ilustrado da figura 5. Após analisar o custobenefício e a facilidade de obtenção de eletretos até mesmo em reciclagem de microfones, foi considerado o mais adequado para o projeto proposto.

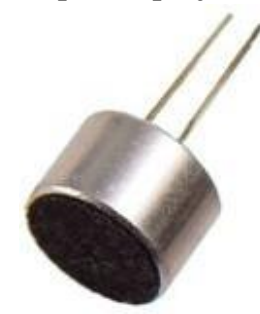

Figura 5. Microfone de Eletreto

A onda sonora é captada pelo eletreto através de uma abertura na parte de cima e movimenta uma folha fina de mylar que é carregada permanentemente em relação a amadura metálica que envolve o sensor. Este movimento altera a indução elétrica na armadura fixa, que está conectada no terminal do transistor interno. Este transistor amplifica o sinal e o entrega ao dreno.

Os microfones de eletreto são da família dos eletrostáticos e o que o diferencia de outros microfones, como os dinâmicos, é que alguns modelos necessitam de alimentação exterior.

O sinal gerado pelo microfone de eletreto possui uma amplitude relativamente pequena, o que dificulta a leitura direta através do conversor analógico-digital do microcontrolador utilizado. Para possibilitar a leitura de tensão proveniente do eletreto, o sinal de 
saída passa por um circuito de amplificação, o qual terá a amplitude aumentada, mas com a mesma frequência.

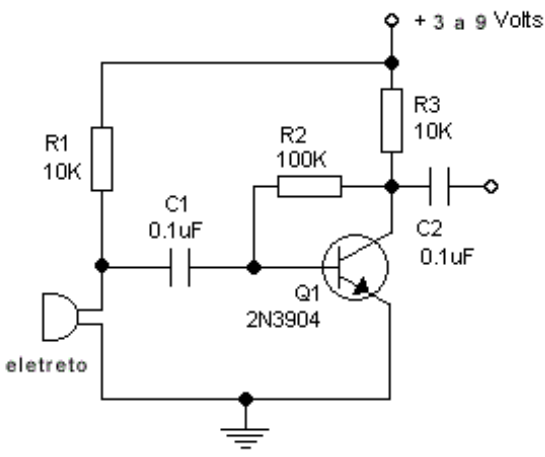

Figura 6. Circuito de amplificação

\subsection{Leitura e Temporização}

O sistema de desenvolvimento SanUSB é uma ferramenta composta de software livre multiplataforma para gravação de microcontroladores da família PIC18Fxx5x com interface USB, pois opera nos sistemas operacionais mais difundidos (Windows $®$, Linux e Mac OSX). O hardware da placa básica da ferramenta é mostrado na figura 7 .

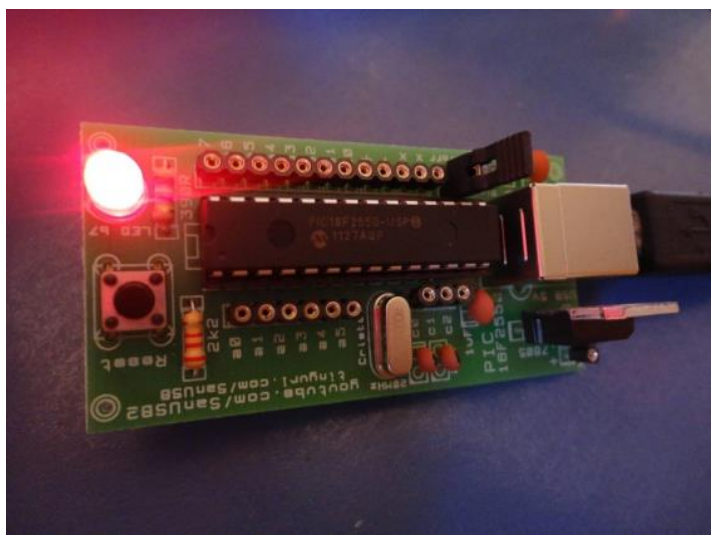

Figura 7. Ferramenta SanUSB

Esta ferramenta livre se mostrou eficiente no desenvolvimento deste projeto, pois não houve a necessidade de remover o microcontrolador para a atualização do firmware. Além disso, o software de gravação de microcontroladores USB é plug and play, ou seja, é reconhecido automaticamente pelos sistemas operacionais sem a necessidade de instalar nenhum driver (Grupo SanUSB, 2011).

A temporização de reconhecimento dos sinais sonoros emitido por uma palma é realizada através de um filtro digital programado no firmware microcontrolador. O firmware do sistema embarcado realiza leituras constantes na tensão de entrada do conversor analógico-digital aguardando um ruído de amplitude específica. Quando a variação positiva do sinal do ruído de amplitude específica é detectada, o sistema aguarda 100 milissegundos (delay) e realiza outra leitura, a qual deverá detectar uma queda na tensão do sinal e novamente aguarda 100 milissegundos para realizar a terceira leitura, a qual deverá ser outro pico de tensão. Após novamente 100 milissegundos é realizada a ultima leitura do ciclo que deverá ser outra queda tensão. Caso seja comprovado pelo firmware que houve a comprovação das quatro etapas com amplitude mínima e na frequência programada o relé de acionamento é energizado.

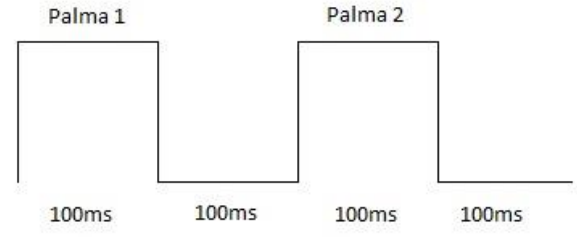

Figura 8. Temporização

A figura 8 mostra o protótipo de acionamento de carga CA controlado por ondas sonoras uqe pode se que pode se utilizado em automação de processos industriais ou em domótica que aborda a automação de processos residenciais ou comerciais.

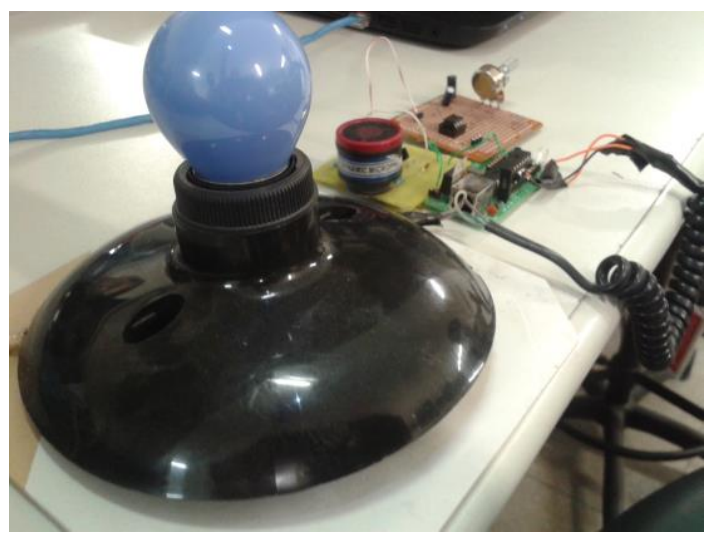

Figura 8. Protótipo do acionamento de carga CA controlado por ondas sonoras

Esse padrão pode ser reproduzido através de duas palmas ou através de dois sons de frequências equivalentes. O desligamento do relé é realizado da mesma forma que a energização.

\section{Contribuições deste trabalho}

Este trabalho abordou um projeto construído com conceitos de eletrônica e programação, abordando tópicos como:

1. Domótica, pois com a junção de eletrônica e programação foram criados diversos dispositivos que hoje facilitam o acionamento de cargas e eletrodomésticos;

2. Incentivo ao desenvolvimento de projetos com sistemas embarcados;

3. A difusão de conceitos de componentes como eletreto de microfone, fonte simétrica, 
circuito de amplificação e ferramenta SanUSB, que são soluções que podem ser aplicadas em inúmeros projetos;

4. A diminuição do custo final de projetos utilizando reciclagem de componentes eletrônicos e o incentivo ao uso de ferramentas e softwares livres.

5. A aplicação prática de assuntos abordados em eletrônica analógica e digital, bem como na programação de microcontroladores.

\section{Conclusões}

Vislumbrando que, atualmente, a eletrônica apresenta a maioria dos projetos vinculados a sistemas computacionais, foi desenvolvido um sistema embarcado para aplicar conceitos de eletrônica digital, analógica, bem como de linguagens de programação e sistemas embarcados. Este projeto foi idealizado para ser utilizado no laboratório de eletrônica como objeto de uso comum e como pesquisa para outros projetos relacionados.

Este trabalho descreveu o desenvolvimento de um sistema de controle de cargas através de ondas sonoras, captadas através de um microfone de eletreto, com amplitude aumentada através de um circuito de pré-amplificação, o qual foi alimentado por uma fonte simétrica de tensão regulável projetada também com o uso de amplificador operacional. Após a conclusão de construção e programação do sistema embarcado, o acionamento de cargas CA com comandos sonoros foi realizado com resultados obtidos conforme o projetado.

\section{Agradecimentos}

Os autores agradecem primeiramente a Deus, por estar sempre presente, como também ao IFCE, pelo suporte e bolsa de pesquisa concedida ao primeiro autor, e ao DAAD (Deutscher Akademischer Austauschdienst) pela bolsa de doutorado sanduíche concedida ao último autor.

\section{Referências Bibliográficas}

Grupo SanUSB (2013). Ferramenta SanUSB. Disponível em http://www.tinyurl.com/SanUSB.

Turner, L. W. (2004). Eletrônica Aplicada, $4^{\text {a }}$ Edição, Editora Hemus.

Wendling, M. (2010). Amplificadores Operacionais, Campus de Guaratinguetá. Universidade Estadual Paulista.
Schildt, H. (1996), C completo e total, $3^{\text {a }}$ Edição, Editora Makron Books. 